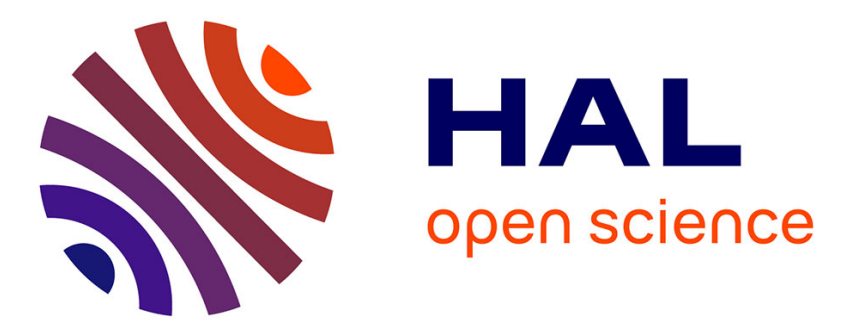

\title{
Cost Modelling Approach for the Source Specific Evaluation of Alternative Manufacturing Networks
}

\author{
Christina Reuter, Jan-Philipp Prote, Torben Schmitz
}

\section{To cite this version:}

Christina Reuter, Jan-Philipp Prote, Torben Schmitz. Cost Modelling Approach for the Source Specific Evaluation of Alternative Manufacturing Networks. IFIP International Conference on Advances in Production Management Systems (APMS), Sep 2016, Iguassu Falls, Brazil. pp.615-623, 10.1007/9783-319-51133-7_73. hal-01615719

\author{
HAL Id: hal-01615719 \\ https://hal.inria.fr/hal-01615719
}

Submitted on 12 Oct 2017

HAL is a multi-disciplinary open access archive for the deposit and dissemination of scientific research documents, whether they are published or not. The documents may come from teaching and research institutions in France or abroad, or from public or private research centers.
L'archive ouverte pluridisciplinaire HAL, est destinée au dépôt et à la diffusion de documents scientifiques de niveau recherche, publiés ou non, émanant des établissements d'enseignement et de recherche français ou étrangers, des laboratoires publics ou privés. 


\title{
Cost Modelling Approach for the Source Specific Evaluation of Alternative Manufacturing Networks
}

\author{
Christina Reuter, Jan-Philipp Prote, and Torben Schmitz \\ RWTH Aachen University, Aachen, Germany \\ \{c.reuter, j.prote, t.schmitz\}@wzl.rwth-aachen.de
}

\begin{abstract}
In order to seize the full potential of production on a global scale, companies need to constantly evolve their production networks and reconsider the number of sites. Decision making in this context forces corporations to process a substantial amount of information and complexity. Prominent examples of German companies (e.g. Stihl or Steiff) prove the present struggle of decision makers. Existing approaches are either too complex and effortful or they do not consider all decision relevant cost factors in a cause-fair way. This paper presents a pragmatic cost modelling approach which focuses on the identification and projection of decision relevant cost factors as well as their source specific allocation in terms of the impact on existing sites in the network.
\end{abstract}

Keywords: Global Supply Networks·Manufacturing Networks-Location Decisions. Cost Modelling. Source Specific Cost Allocation

\section{Challenges within the Evaluation of Alternative Global Manufacturing Networks}

Producing companies nowadays mostly operate in global manufacturing networks consisting of globally spread production sites. These networks are mainly determined by the quantity and the geographical distribution of its production sites. Evaluating alternative network scenarios in terms of adjusted number of sites is therefore one important mean to elaborate a manufacturing network. However, as recent research studies of the Fraunhofer ISI show, companies struggle with designing global manufacturing networks and location decision making in particular: $25 \%$ of locations decisions made by German companies needed to be revoked [1]. Four major challenges within location decisions can be identified: The first challenge is the missing transparency about decision relevant (cost) information. In a production network each site is under the influence of a variety of internal and external interdependencies (e.g. cross-linkages to other sites and suppliers as well as the development of markets and economical or political conditions). Many managers, especially in SME, are overwhelmed by the complexity of the decision situation [2]. Therefore it is necessary to establish transparency by understanding the cause-effect relationship between costs and cost drivers. Another shortcoming is the availability and validity of decision relevant cost data. The required accounting information might not be available or only in the local location controlling which decision makers might not want to incorporate in the process for confidentiality reasons. 
Moreover local controlling divisions are still given an ample scope so that it takes high efforts to ensure the comparability of cost information.

Studies showed that misvalued cost advantages were the main reason for companies to revoke their location decision. On the one hand cost savings, flexibility and quality are overvalued while on the other hand, time and investment efforts are often underestimated [3]. Especially during the startup phase a potential new location needs to be supported and coordinated. In many cases the resulting overhead costs are not allocated to the causing new location but to the existing locations. Moreover the impact on existing sites in the network is often neglected. A new site might cause a structural cost impact on existing locations if for example complete product lines or only production volumes are relocated. Fixed costs for staff, production area or equipment cannot fully be adapted to the declining production volumes. This phenomenon is known as cost stickiness [4]. It leads to a lower productivity and ability to bear overhead costs in the existing sites. In general, the shift of fixed costs across the network is not duly taken into account.

To contribute to solving these deficits this paper pursues the following objectives:

- Systematical and comprehensible cost modelling using cost drivers

- Allocation of relevant costs in a source-specific way (in terms of the decision situation) to depict impact on existing sites

- Pragmatical approach to ensure applicability in industrial practice

\section{Deficiencies of Existing Approaches}

In the following state of the art section a cross selection of contemporary research on cost modelling and decision support in the field of evaluating alternative global production networks is presented.

Vahdani and Mohammadi present a bi-objective optimization model for supply chains aiming at the minimization of total costs and waiting times in services. Their cost model includes fixed costs, transportation costs, manufacturing costs as well as distribution costs. The cost model is combined with a priority queuing system and enriched by a uncertainty approach. To verify the results of the model various theoretical experiments are performed, no actual cost data however is utilized. The cost model does not depict costs in detail which change within a location decision. The modeling effort for costs is high since a closed loop supply chain is considered [5].

Schuh et al. developed the software tool OptiWo for the optimization of manufacturing networks. By the use of an optimization algorithm and a total landed cost function complete networks are modeled and evaluated. As the method focuses on a balanced state of a production network not all relevant costs are presented detailed enough to support single location decisions [6].

A mixed integer programming model for integrated production and distribution planning is introduced by Yuan et al.. They utilize a branch-and-bound algorithm to assign multiple products to a certain numbers of sites and warehouses which distribute to the customers. The approach implicates a low modelling effort, while the focus however is mostly on costs for opening up and operating warehouses [7]. 
Wagner and Nyhuis deliver an approach for a global manufacturing system for product variants. Especially the needs of SME which often produce a variety of products with high demands on quality are taken into account. Production systems are designed and evaluated by a cost based system for relocation decisions. As a first step, the actual state is analyzed based on the total cost of ownership. Afterwards various scenarios are created to enable an evaluation of different locations [8].

Christodoulou et al. provide an approach with 4 phases for the continuous configuration and improvement of production networks. The first step is to understand the need for change and to define a network strategy. Afterwards a Make-or-Buy analysis is made to find the products that should be considered. A multi-stage approach is used to determine the suitable manufacturing location of each product. Finally the relocation process is planned. The decision making process is rather in focus than a profound cost modelling [9].

To support location decisions Yang uses the AHP decision model which allows comparing decision-makers preferences with location characteristics. The cost modeling however is not very profound. By evaluating alternative sites under both quantitative and qualitative factors it is possible to take managerial experience and judgement into account [10].

All in all it can be stated that several approaches in this field exist. Especially the cost modeling approaches are quite effortful and time-consuming. Most approaches do not consider all required cost elements, which are affected by a location decision, in a source specific way. Neither do they offer the possibility to calibrate the cost model using (aggregated) actual costs. Thereby an opportunity to improve the methods validity is missed.

\section{Cost Modelling Approach for the Source Specific Evaluation}

In this paper we present a new cost modelling approach which enables a pragmatic cost modelling of decision relevant cost types based on cost drivers and the consumption of resources. Special attention is paid to source specific evaluation of the impact on existing sites in the network. The model consists of four phases. In the preparation phase the decision situation is specified (e.g. concrete objectives, data availabilities and implications) and the level of aggregation as well as the decision relevant cost types are derived based on the specifics of the decision situation. In the second step the operational cost model is built in a combined top down/bottom up approach to use the modeled and calibrated actual costs as basis for prediction of costs in the decision scenarios. An extended evaluation model is used in the next step to evaluate the additional costs associated with the decision (e.g. investments, transaction costs) and to include the structural impact on existing sites (e.g. sticky costs) in the assessment. Lastly a decision support is built to efficiently evaluate alternative network scenarios by a profitability calculation and a source specific unit cost comparison. The overall approach is outlined in a comprehensive overview in Figure 1.

The operational cost model and the source specific evaluation model (steps two and three) as the core of this paper are depicted in more detail in the following. Further 


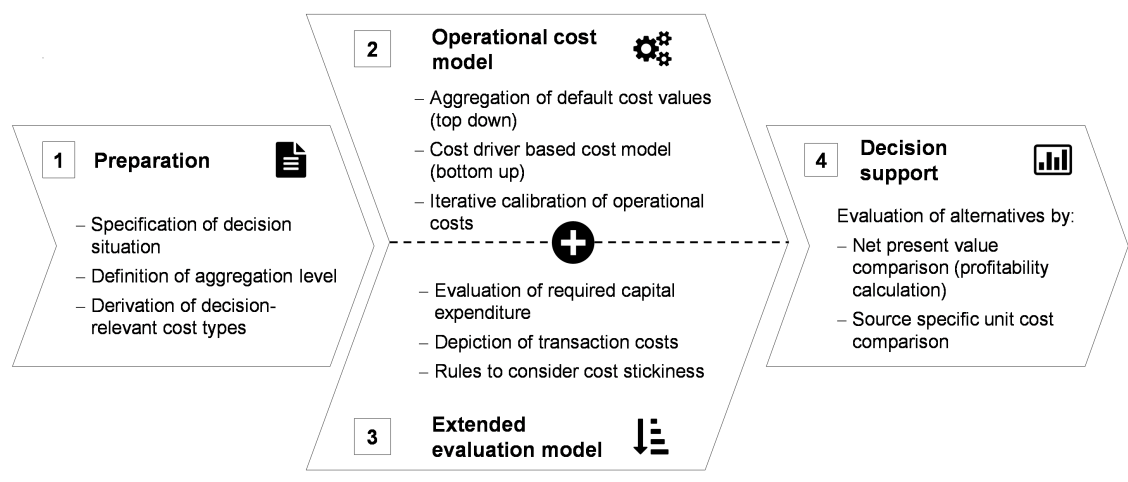

Fig. 1. Source specific cost modelling approach

information on the preparation phase, especially the derivation of decision relevant cost types, can be found in Reuter et al. [11].

\section{Operational Cost Model and Calibration}

The objective of the operational cost model is to depict all decision relevant costs of one product group in a pragmatic way and allow decision makers to track the costs back to their causing source. For this purpose, the resource-based cost modeling approach for product variants of Schuh is adapted to the specifics of a location decision process [12]. The detailed operational cost modeling approach is shown in Figure 2.

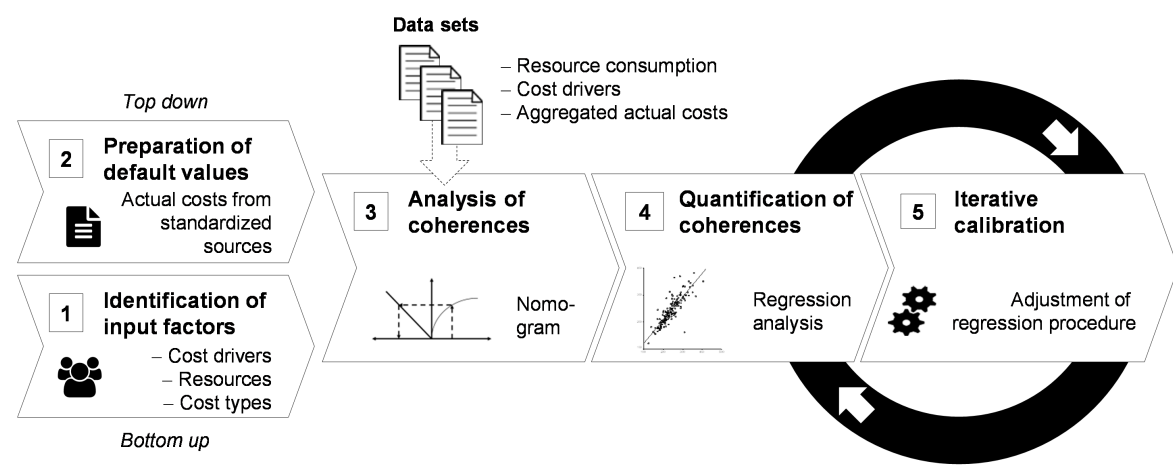

Fig. 2. Operational cost modelling approach

The model consists of a twofold top down/bottom up approach to derive the required data and parameters. The bottom up stream defines the basic set of cost types, resources and cost drivers which represent the cost consumption. The top down part prepares 
and aggregates actual costs from standardized sources like the external accounting for example in order to assign these cost information to the defined cost types. Both streams are merged in the next step and the coherences between cost drivers, resources and resulting costs are analyzed and quantified. The approach is based on the idea, that a cost driver is responsible for a certain resource consumption (e.g. produced quantity of a product group). This correlation can be formalized in a consumption function. The resource consumption (e.g. weight of raw materials) in turn causes costs (e.g. raw material costs). The correlation might be formalized in a cost function. The coherence of both functions can best be visualized by the use of a simplified nomogram shown in the following Figure 3.

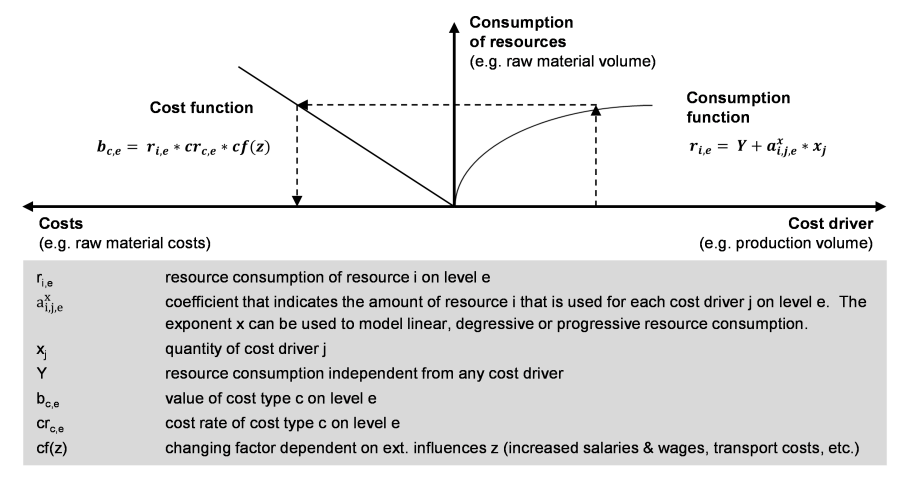

Fig. 3. Example of a nomogram and equations

\subsection{Work Guideline}

The effect of each cost driver on the consumption of its corresponding resource and ultimately on the related cost type is modeled individually but can be depicted by one mathematical equation that integrates both functions. In order to quantify the consumption function as well as the cost function, a regression analysis will be conducted. In a first step a standard ordinary least square (OLS) regression is used to predict the corresponding cost value (e.g. material costs) as the dependent variable. OLS is a standardized, easy to use statistical method for estimating the relationships among variables. Stock \& Watson provide detailed information on OLS [13]. In order to conduct the OLS, actual data sets with several points in time (e.g. years 2013-2015) are needed which should provide information on the resource consumption, the value of the cost drivers and the corresponding actual costs. In order to ensure comparability, the numerical values of each set of data has to be prepared: inflation induced effects on costs as well as any one time special effects which do not correlate with the regular serial production need to be eliminated. Once the OLS delivers a first quantification of the coherences, the consumption and cost function can be validated by predicting the actual costs of the latest data set. Hereto only values for the cost drivers of the corresponding 
data set are needed. If the predicted costs are not sufficiently close to the actual costs (e.g. measured with the mean square error or root mean square error), the cost model can be calibrated iteratively by trying out different regression models. These procedures include generalized least squares analysis (GLS) or nonlinear regression.

The procedure of cost modelling is done for all cost types (per product group) and for all focused product groups. A complete overview of all relevant cost types, resources and cost drivers can be found in another paper presented by the authors [14].

\subsection{Extended Cost Evaluation Model}

The extended evaluation model is used to evaluate the additional costs associated with the decision (e.g. investments, transaction costs) and to include the structural impact on existing sites through cost stickiness in the assessment. Investments as well as transaction costs (e.g. costs for coordination and control, travel expenses, trainings and educations, etc.) are well known concepts which do not need further detailing, since several approaches illustrate their consideration. [e.g. 3] Sticky costs however are not yet integrated in the location decision making process. They represent the potential negative impact a new site has on existing ones since their ability of bearing overhead costs is weakened. This is particularly the case for building costs, salaries and partly for machinery and equipment costs. If production volumes or complete products are relocated to a new location, idle capacities in terms of production and office area, management capacities and machinery and equipment are left at the original site. These idle capacities cannot be reduced immediately. A factory manager for example cannot be paid $80 \%$ of his salary if $20 \%$ of "his" products are relocated. The value of these idle capacities (fixed costs) can be interpreted as sticky costs.

The operational model (c.f. chapter 3.1) can be used to determine the level of cost stickiness per product group in the three cost types by using the corresponding cost drivers.

\subsection{Decision support}

The decision support incorporates the data from the cost models and combines a standard profitability calculation using the net present value (NPV) with a source specific unit cost comparison. The NPV focuses on the purely cash-based effects of the potential new site while the unit cost comparison includes implicit costs such as sticky costs in order to ensure a source-specific evaluation for the specific decision situation. A source-specific unit cost comparison provides transparency about the structural impact of the decision for the complete production network and helps to reduce the weight of allegedly short term cost advantages which lower wage levels might offer. Sticky costs however might easily overcompensate the wage level advantage. The following industrial case study illustrates the source specific unit cost comparison using a concrete example of one product group. 


\section{First Case Study and Basic Validation}

The approach is provisionally validated with an industrial partner in the metal working industry. Objective of the bilateral project was the preparation of a decision paper for a potential new location in eastern europe. The management wanted to know whether the partly relocation of production capacities would make sense in order to utilize lower factor costs as a typical profitablity calculation (NPV based) indicated. The results of the source-specific cost modelling approach are shown in Figure 4 exemplarily for one product group as a unit cost comparison. By explicitly considering the sticky costs associated with the decision situation it becomes obvious that the savings in purchase and labour are overcompensated by the cost stickiness of building costs and salaries of the remaining management functions.

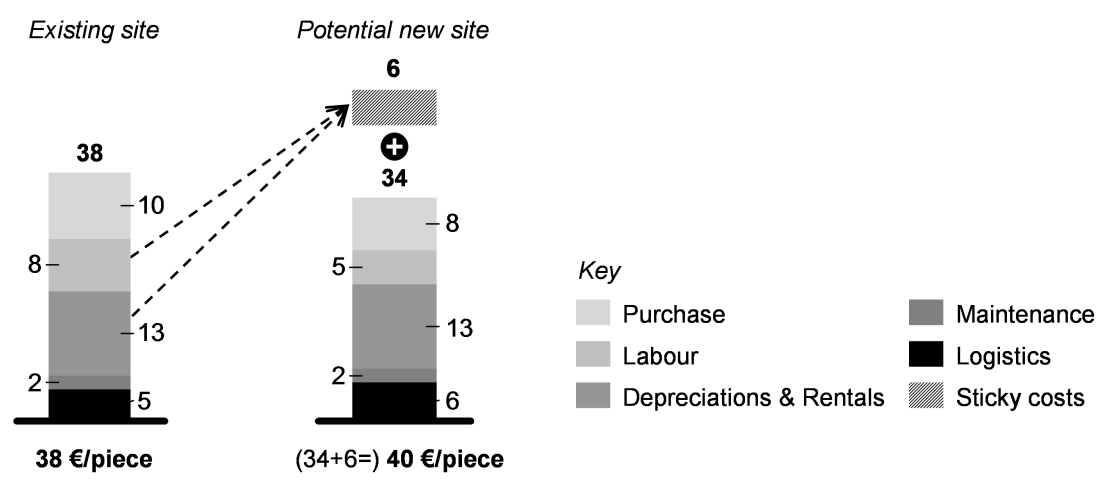

Fig. 4. Exemplary unit cost comparison for one product group

All in all, this first case study proved the general applicability of the source specific cost modelling approach. Transparency regarding the decision specific cause-fair shift of fixed costs could be established.

\section{Conclusions}

The approach presented in this paper offers a pragmatic cost modelling method to improve location decisions by evaluating alternative manufacturing in a more source specific way through explicitly considering the impact on exiting sites. The cost model enables decision makers to gain more transparency on the cause and effect relationships between drivers, resource consumption and resulting costs. The impact on existing locations in terms of a weaker ability to bear fixed costs can be evaluated and integrated in the decision. The approach was validated with an SME. Further research needs to be done on how to handle special effects (e.g. productivity growth, periodic variations) and on how to include a degradation rate for cost stickiness. More validation needs to be done to further detail the approach and to ensure applicability in various fields/sectors. 
Acknowledgement The authors would like to thank the German Research Foundation DFG for the kind support within the Cluster of Excellence "Integrative Production Technology for High-Wage Countries".

\section{References}

1. Zanker, C., Kinkel, S., Maloca, S.: Globale Produktion von einer starken Heimatbasis aus. Mitteilungen aus der ISI-Erhebung zur Modernisierung der Produktion 63 (2013)

2. Abele, E., Kluge, J.: How to Go Global-Designing and Implementing Global Production Networks. McKinsey \& Company, Inc (2005)

3. Abele, E., Meyer, T., Näher, U., Strube, G., Sykes, R. (eds.): Global Production. Springer Berlin Heidelberg, Berlin, Heidelberg (2008)

4. Dalla Via, N., Perego, P.: Sticky Cost Behaviour: Evidence from Small and Medium Sized Companies. Accounting \& Finance 54(3), 753-778 (2014)

5. Vahdani, B., Mohammadi, M.: A Bi-Objective Interval-Stochastic Robust Optimization Model for Designing Closed Loop Supply Chain Network with Multi-Priority Queuing System. International Journal of Production Economics 170, 67-87 (2015)

6. Schuh, G., Potente, T., Varandani, R., Schmitz, T.: Global Footprint Design based on genetic algorithms-An "Industry 4.0" Perspective. CIRP Annals-Manufacturing Technology 63(1), 433-436 (2014)

7. Yuan, X.M., Low, J.M., Yeo, W.M.: A Network Prototype For Integrated ProductionDistribution Planning With Non-Multi-Functional Plants. International Journal of Production Research 50(4), 1097-1113 (2012)

8. Wagner, C., Nyhuis, P.: A Systematic Approach To Analysis And Design Of Global Production Networks. Production Engineering 3(3), 295-303 (2009)

9. Christodoulou, P., Fleet, D., Hanson, P.: Making the right things in the right places. University of Cambridge, IfM Publication (2007)

10. Yang, J., Lee, H.: An AHP Decision Model For Facility Location Selection. Facilities 15(9/10), 241-254 (1997)

11. Reuter, C., Prote, J.P. and Pohlig, D: Approach for the Cause-fair Allocation of Costs in Location Decisions in Global Production Networks. In: Proceedings of Abstract and Papers of ICPR23. Manilla (2015)

12. Schuh, G.: Produktkomplexität Managen: Strategien-Methoden-Tools. Carl Hanser Verlag GmbH Co KG (2014)

13. Stock, J.H., Watson, M.W.: Introduction to Econometrics, vol. 104. Addison Wesley Boston (2003)

14. Reuter, C., Prote, J., Schmitz, T.: A Top-down/bottom-up Approach for Modeling Costs of a Manufacturing network. In: Proceedings of the 23rd EurOMA Conference. Trondheim (2016) 